\title{
On the Pre-treatment of Pig Iron by Continuous
}

\section{Dephosphorization Furnace*}

\author{
By Akira FUKUZAWA, Ryuichi NAKAGAWA, Shiro YOSHIMATSU, \\ Akira SATO, Tatsuro MITSUI and Tsuyoshi OZAKI**
}

\begin{abstract}
Synopsis
Continuous pre-dephosphorization process with $300 \mathrm{~kg}$ trough type furnace was examined at the hot metal input rate of 33 to $38 \mathrm{~kg} / \mathrm{min}$, oxygen blowing rate of $0.7 \mathrm{Nm}^{3} / \mathrm{min}$, and flux input rate of 4 to $5 \mathrm{~kg} / \mathrm{min}$. The slag was cocurrent with the metal. As the result of 1 lance and 2 lances operations, it became clear that the 2 lances operation was more advantageous for enhancing slag-metal reactions as predicted from the characteristics of the resistance model. Moreover, a theoretical analysis confirmed that the slag-metal reactions could proceed most effectively when the gasliquid flow rate ratio \{(oxygen blowing rate $+\mathrm{CO}$ gas generating rate)/hot metal rate for each lance was kept equal.

By utilizing the result of this investigation, it would be possible to develop a continuous hot metal pre-treatmenl process with higher dephosphorization ability by optimizing the physical conditions of the process and by adopting countercurrent operation.
\end{abstract}

\section{Introduction}

In recent years, phosphorus content in the raw materials for iron making tends to increase, whereas demands for low phosphorus quality steel keep increasing. Under these circumstances the development of an effective method of dephosphorization is strongly expected in the steelmaking process. By now, various kinds of dephosphorization processes have been reported. ${ }^{1-3)}$ Technically, each process can provide low phosphorus steel, but none of them seems to have been established as a process with economically prevailing potential.

One of the characteristics of NRIM multi-stage trough type continuous steelmaking process ${ }^{4-6)}$ is in its high dephosphorization capability. The process can be regarded as a continuous double-slagging method because of the existence of slag-off port at each stage. In the last 10 operations, the process showed the dephosphorization rate of 60 to $90 \%$ in the lst stage where carbon level is as high as $3 \%$. This suggests that the process is advantageous for dephosphorization as compared with the converter process. Making the use of this characteristic, and aiming to investigate the possibility of the continuous preliminary dephosphorization process where the decarburization is depressed but the dephosphorization is promoted, experiments were made with a small scale trough type dephosphorization furnace. In the experiments the relation between the number of lances and the progress of slag-metal reaction is examined by making reference to the characteristics of the resistance model previously developed. ${ }^{7,8)}$

\section{Experimental Equipment and Procedure}

The continuous preliminary dephosphorization equipment is shown in Fig. 1 and the furnace dimension in Fig. 2. Inner width of the furnace was $25 \mathrm{~cm}$, and the position of metal outlet port was so decided as to make the still bath depth $15 \mathrm{~cm}$. The metal hold-up weight was about $300 \mathrm{~kg}$. The lance was vertically positioned at $36 \mathrm{~cm}$ from the metal inlet side. In the 2 lances operation, the 2 nd lance was set $25 \mathrm{~cm}$ farther. The lance height from the still metal bath surface was $15 \mathrm{~cm}$ in the 1 lance experiments, and $5 \mathrm{~cm}$ in the 2 lances experiments. Straight nozzle with 4.9 or $3.4 \mathrm{~mm}$ inner diameter was used.

Input rate of hot metal was controlled by means of the predetermined angular velocity of tilting of the holding furnace and $9 \mathrm{~mm}$ dia. nozzle at the bot-

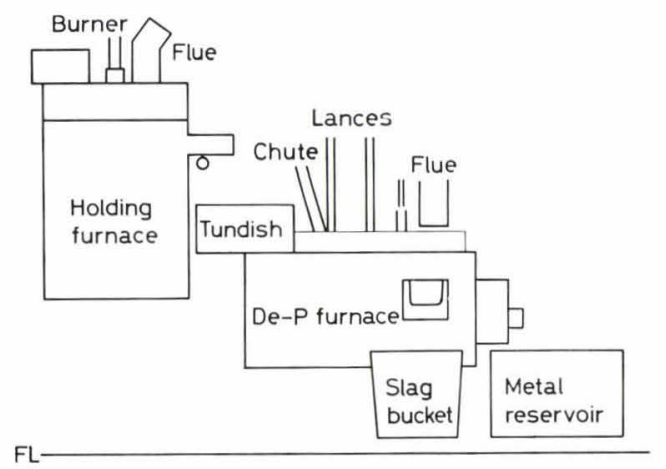

Fig. 1. Experimental equipment for continuous dephosphorization process

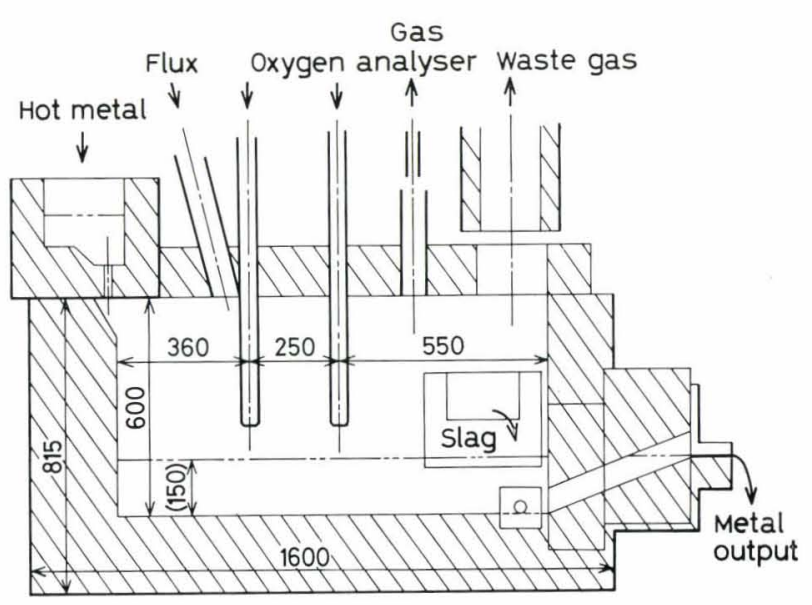

Fig. 2. Construction of the continuous dephosphorization furnace

* Originally published in Tetsu-to-Hagané, 64 (1978), 2109, in Japanese. English version received January 8, 1979.

** National Research Institute for Metals, Nakameguro, Meguro-ku, Tokyo 153. 
tom of the tundish. Oxygen gas blowing rate was regulated by the oxygen feeding system reported previously. ${ }^{4)}$ Flux was added through the chute which led the flux to the fire point underneath the 1st lance. The grain size of the flux ranged approximately from $2 \mathrm{~mm}$ to $7 \mathrm{~mm}$. One hour before the operation started, $40 \mathrm{~kg}$ of flux was added into the furnace. The composition of the flux in weight ratio was lime: fluorspar: slag of previous experiment $=5$ : $1: 2$. The flux composition ratio in continuous operation was lime: silica sand: iron ore: fluorspar: bauxite $=10: 2: 3: 3: 3$. Chemical analysis of each material is listed in Table 1. Out of $1.7 \mathrm{t}$ of hot metal melted by an electric furnace, $1.4 \mathrm{t}$ was teemed into the holding furnace and the rest into the dephosphorization furnace. As for the start-up, semi-batch method ${ }^{7)}$ was adopted, i.e., $0.5 \mathrm{Nm}^{3} / \mathrm{min}$ of oxygen was preliminarily blown until the completion of the preparation, and the experiment was started by increasing the blowing rate of oxygen to $0.7 \mathrm{Nm}^{3} / \mathrm{min}$ when the hot metal flowed into the furnace at the aimed rate of $40 \mathrm{~kg} / \mathrm{min}$. Sampling of metal and slag, and temperature measurement were done at $5 \mathrm{~min}$ interval. Besides, during the preliminary blow forced mixing with a stirrer was done for the promotion of faster slag formation.

Operational conditions of 6 experiments are listed in Table 2. Higher blowing rate of oxygen was employed in the lst experiment to avoid the thermal problem which is inherent in a small scale experiment and to accustom the operators to blowing. The lance height for the 1 lance operation was so decided as the velocity of oxygen jet at the still bath surface becomes about $100 \mathrm{~m} / \mathrm{sec}$ with $4.9 \mathrm{~mm}^{\text {क nozzle as }}$ reported in Ref. 4). The lance height for the 2 lances operation was decided, on the basis of Fig. 5 of Ref. 4), by assuming that the velocity is proportional to the flow rate. In experiments Nos. 4 and 5, $3.4 \mathrm{~mm}^{\phi}$ nozzle was used to get a blowing condition harder than that in experiments Nos. 3 and 2. The conditions for No. 6 were the same with that for No. 2. Aimed flux addition of $5 \mathrm{~kg} / \mathrm{min}$ in experiments Nos. 4 and 5 was to prevent the lowering of dephosphorization rate in the hard blow operation. For other experiments flux was added at $4 \mathrm{~kg} / \mathrm{min}$.

\section{Results and Discussion}

The results of experiments are summerized in Table 2. As an example of the operation, the result of No. 3 is shown in Fig. 3. Though the advance of reactions in semi-batch operation depends on the delay of the start of burning, degree of slag formation and time required for preperation, stable output composition and temperature can be obtained immediately after the start of the continuous operation if the blowing during the semi-batch period is properly made. Samples of semi-batch period were taken from the slag-off port. Increase in phosphorous content $(\underline{P})$ observed after $30 \mathrm{~min}$ in the figure arises because the flux addition was stopped. Each value listed in Table 1 is the mean value of three measurements made when the operation can be regarded to be in a steady state, i.e., after about $20 \mathrm{~min}$ from the start of the operation. Slagging of flux was fully attained in each experiment, and residual lime was not noticed except for experiment No. 5.

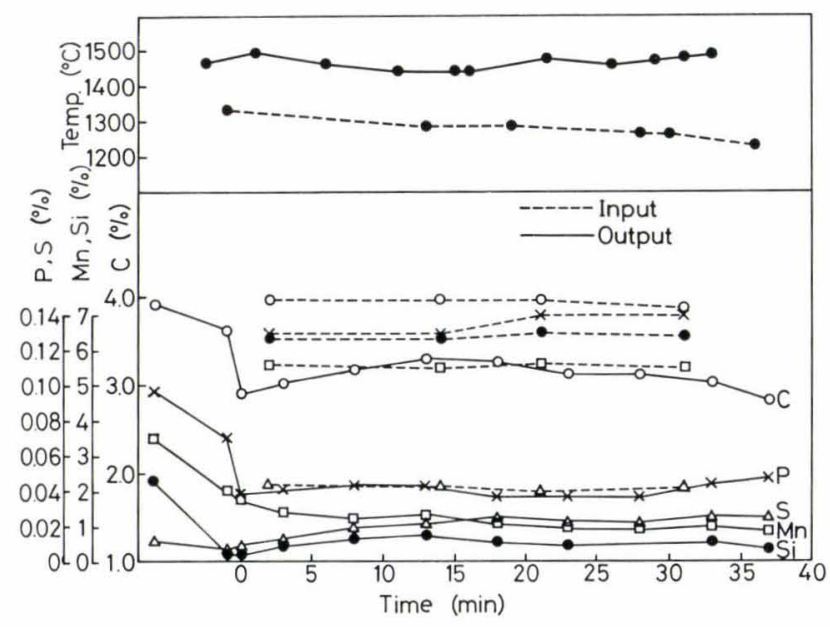

(a) Metal

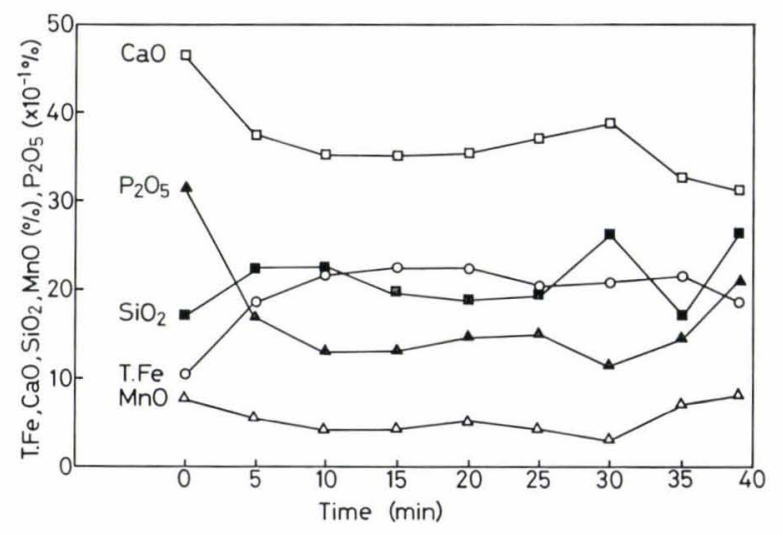

(b) Slag

Fig. 3. Operational results of experiment No. 3

Table 1. Chemical compositions of flux materials

\begin{tabular}{|c|c|c|c|c|c|c|c|c|c|}
\hline \multirow{2}{*}{ Materials } & \multicolumn{9}{|c|}{ Chemical compositions (\%) } \\
\hline & $\mathrm{CaO}$ & $\mathrm{CaCO}_{3}$ & $\mathrm{CaF}_{2}$ & $\mathrm{SiO}_{2}$ & $\mathrm{Fe}_{2} \mathrm{O}_{3}$ & $\mathrm{Al}_{2} \mathrm{O}_{3}$ & $\mathrm{TiO}_{2}$ & $\mathrm{P}$ & $\mathrm{S}$ \\
\hline Lime & 83.80 & 1.08 & & 0.25 & 0.04 & & & 0.006 & 0.11 \\
\hline Fluorspar & & 2.97 & 70.89 & 21.90 & & & & 0.003 & 0.13 \\
\hline Silica sand & & & & 95.30 & 0.29 & & & & 0.32 \\
\hline Iron ore & 0.06 & & & 3.31 & 95.44 & 1.67 & & 0.037 & 0.014 \\
\hline Bauxite & & & & 4.08 & 5.21 & 58.90 & 2.48 & & \\
\hline
\end{tabular}


Table 2. Results of experiments

Number of experiment

$2 \quad 3$

4

5

$6 \quad$ NRIM*

\begin{tabular}{|c|c|c|c|c|c|c|c|c|c|}
\hline \multicolumn{10}{|l|}{ Lancing conditions } \\
\hline Number of lances & & 1 & 1 & 2 & 2 & 1 & 1 & 4 \\
\hline Nozzle diameter & \multicolumn{2}{|c|}{$(\mathrm{mm})$} & 4.9 & 4.9 & 4.9 & 3.4 & 3.4 & 4.9 & 4.9 \\
\hline Lance height & \multicolumn{2}{|c|}{$(\mathrm{mm})$} & 150 & 150 & 50 & 50 & 150 & 150 & 150 \\
\hline Distance between lances & \multicolumn{2}{|c|}{$(\mathrm{mm})$} & & & 250 & 250 & & & 250 \\
\hline Input rate of pig iron & \multicolumn{2}{|c|}{$(\mathrm{kg} / \mathrm{min})$} & 33.5 & 37.6 & 33.5 & 37.8 & 37.2 & 37.7 & 130 \\
\hline Flux rate & \multicolumn{2}{|c|}{$(\mathrm{kg} / \mathrm{min})$} & 4.47 & (4) & 4.06 & 5.31 & 5.23 & 4.21 & 10.5 \\
\hline Oxygen blowing rate & \multicolumn{2}{|c|}{$(\mathrm{N} l / \min )$} & 1011 & 687 & 651 & 694 & 716 & 680 & 2340 \\
\hline \multirow{2}{*}{ Temperature of hot metal } & \multirow{2}{*}{$\left({ }^{\circ} \mathrm{C}\right)$} & In & 1330 & 1260 & 1270 & 1360 & 1350 & 1310 & 1406 \\
\hline & & Out & 1497 & 1477 & 1457 & 1465 & 1468 & 1503 & 1504 \\
\hline \multirow{5}{*}{ Composition of pig iron } & \multirow{5}{*}{$(\%)$} & $\mathrm{C}$ & 3.67 & 3.95 & 3.96 & 4.04 & 3.98 & 4.05 & 3.89 \\
\hline & & $\mathrm{Si}$ & 0.46 & 0.51 & 0.64 & 0.62 & 0.61 & 0.60 & 0.57 \\
\hline & & $\mathrm{Mn}$ & 0.52 & 0.56 & 0.56 & 0.52 & 0.56 & 0.56 & 0.56 \\
\hline & & $\mathrm{P}$ & 0.13 & 0.13 & 0.14 & 0.12 & 0.14 & 0.14 & 0.13 \\
\hline & & $\mathrm{S}$ & 0.018 & 0.016 & 0.042 & 0.049 & 0.047 & 0.051 & 0.034 \\
\hline \multirow{5}{*}{ Composition of output metal } & \multirow{5}{*}{$(\%)$} & $\mathrm{C}$ & 1.55 & 3.03 & 3.16 & 3.11 & 3.40 & 3.09 & 2.88 \\
\hline & & $\mathrm{Si}$ & 0.014 & 0.044 & 0.051 & 0.047 & 0.10 & 0.082 & $<0.01$ \\
\hline & & $\mathrm{Mn}$ & 0.059 & 0.10 & 0.10 & 0.085 & 0.16 & 0.12 & 0.28 \\
\hline & & $\mathrm{P}$ & 0.020 & 0.041 & 0.037 & 0.037 & 0.065 & 0.049 & 0.025 \\
\hline & & $\mathrm{S}$ & 0.014 & 0.012 & 0.022 & 0.029 & 0.026 & 0.030 & 0.019 \\
\hline \multirow{12}{*}{ Composition of slag } & \multirow{12}{*}{$(\%)$} & T. $\mathrm{Fe}$ & 21.20 & 23.77 & 20.94 & 14.03 & 19.68 & 21.89 & 5.42 \\
\hline & & $\mathrm{Fe}_{2} \mathrm{O}_{3}$ & 13.84 & 13.56 & 13.10 & 8.59 & 8.67 & 14.73 & 2.64 \\
\hline & & $\mathrm{CaO}$ & 38.30 & 33.97 & 37.18 & 41.71 & 34.34 & 39.49 & 57.50 \\
\hline & & $\mathrm{SiO}_{2}$ & 12.44 & 15.10 & 21.67 & 23.05 & 19.50 & 18.80 & 15.71 \\
\hline & & $\mathrm{MnO}$ & 2.91 & 4.67 & 4.20 & 5.71 & 3.59 & 4.92 & 3.90 \\
\hline & & $\mathrm{P}_{2} \mathrm{O}_{5}$ & 1.06 & 1.38 & 1.39 & 1.65 & 1.33 & 1.34 & 2.19 \\
\hline & & $\mathrm{CaS}$ & 0.07 & 0.12 & 0.15 & 0.16 & 0.14 & 0.16 & - \\
\hline & & $\mathrm{CaF}_{2}$ & 6.42 & 5.26 & 5.97 & 6.63 & 6.54 & 6.83 & 8.05 \\
\hline & & $\mathrm{Al}_{2} \mathrm{O}_{3}$ & 9.93 & 6.98 & 7.70 & 7.74 & 7.86 & 6.87 & - \\
\hline & & $\mathrm{MgO}$ & 0.88 & 0.58 & 0.70 & 0.78 & 0.60 & 0.97 & 3.01 \\
\hline & & $\mathrm{TiO}_{2}$ & 0.74 & 0.87 & 0.82 & 0.99 & 0.89 & 0.90 & - \\
\hline & & $\mathrm{CaO} / \mathrm{SiO}_{2}$ & 3.08 & 2.25 & 1.72 & 1.81 & 1.76 & 2.10 & 3.66 \\
\hline Oxygen efficiency & \multicolumn{2}{|l|}{$(\%)$} & 83.7 & 76.7 & 72.0 & 82.0 & 57.1 & 82.3 & 82.0 \\
\hline \multirow{5}{*}{ Rate of removal } & \multirow{5}{*}{$(\%)$} & $\mathrm{C}$ & 57.8 & 23.3 & 20.2 & 23.0 & 14.6 & 23.7 & 26.0 \\
\hline & & $\mathrm{Si}$ & 97.0 & 91.4 & 92.0 & 92.4 & 83.6 & 86.3 & $>98.2$ \\
\hline & & $\mathrm{Mn}$ & 88.7 & 82.1 & 82.1 & 83.7 & 71.4 & 78.6 & 50.0 \\
\hline & & $\mathrm{P}$ & 84.6 & 68.5 & 73.6 & 69.2 & 53.6 & 65.0 & 80.8 \\
\hline & & $\mathrm{S}$ & 22.2 & 25.0 & 47.6 & 40.8 & 44.7 & 41.2 & 44.1 \\
\hline \multirow{3}{*}{$\begin{array}{l}\text { Relative removal rate of } \mathrm{P} \text { to } \\
\text { other elements }(-)\end{array}$} & & $\mathrm{P} / \mathrm{C}$ & 1.46 & 2.94 & 3.64 & 3.01 & 3.67 & 2.74 & 3.11 \\
\hline & & $\mathrm{P} / \mathrm{Si}$ & 0.872 & 0.749 & 0.800 & 0.749 & 0.641 & 0.753 & $>0.823$ \\
\hline & & $\mathrm{P} / \mathrm{Mn}$ & 0.954 & 0.834 & 0.869 & 0.827 & 0.751 & 0.827 & 1.62 \\
\hline
\end{tabular}

* National Research Institute for Metals

\section{Blowing Conditions and Removal Rate of Each Element}

\section{Influence of the Number of Lance}

The comparison of the removal rate of each element between 1 lance (Nos. 2, 5 and 6) and 2 lances (Nos. 3 and 4 ) operations carried out at nearly equal oxygen blowing rate shows that oxidation of $\mathrm{Si}, \mathrm{Mn}$ and $\mathrm{P}$ or slag-metal reactions are more advanced in the 2 lances operation. On the other hand, the rate of carbon removal owing to gas-metal reaction shows no significant difference between the two types of operations except for No. 5 for which the rate is excessively low. These results have been predicted from the characteristics derived from the resistance model. ${ }^{8)}$ Namely, decarburization rate is proportional to the oxygen feeding rate. For the slag-metal reaction, however, the residual rate of each element increases hyperbolically with the sum of the rate of oxygen gas blowing and that of CO generation. Therefore, one tank is enough for decarburization irrespective 
of whether single nozzle or multiple nozzle lance as far as the bath is mixed well. However, for the slag-metal reaction following types of furnaces are effective: a trough type furnace with multiple lances in series like NRIM process or tank type furnaces in series with 1 lance in each furnace.

As shown in Appendix, the residual rate, $\Phi$, of $\mathrm{Si}$ is given, on the basis of the resistance model ${ }^{8)}$ and on the assumption that one lance makes one backmix tank, by

$$
\Phi=1 /\left(1+\Lambda / \alpha_{\mathrm{Si}}\right)
$$

where, $\Phi=\mathrm{Si}_{\text {out }} / \mathrm{Si}_{\text {in }}$ and $A=\left(V_{\mathrm{CO}}+V_{\mathrm{O}_{2}}\right) / Q$. As the metal flow rate $Q$ can be taken constant, $A$ is the function of $V_{\mathrm{CO}}+V_{\mathrm{O}_{2}}$, or gas flow rate per 1 lance. From this relation, maximum rate of $\mathrm{Si}$ removal ( $\Phi$ becomes minimum) is derived attainable by making the gas flow rate for each lance (tank) equal in the $n$ tanks in series or the trough type model with $n$ lances in series. Residual rate, $\Phi_{n}$, is given as follows :

$$
\Phi_{n}=1 /\left\{1+\Lambda /\left(n \alpha_{\mathrm{si}}\right)\right\}^{n}
$$

The values of $\alpha_{\mathrm{Si}}$ obtained by substituting the operational results into Eqs. (1) and (2) are given in Table 3. The difference in the value of $\alpha_{\mathrm{Si}}$ for each experiment is marked, but the values are scattered around $0.007^{7}$ ) which has been previously obtained. By using this value and assuming $V_{\mathrm{O}_{2}}=1 \mathrm{~kg} / \mathrm{min}$, $V_{\mathrm{CO}}=0.8 \mathrm{~kg} / \mathrm{min}$ and $Q=37 \mathrm{~kg} / \mathrm{min}, \Phi_{1}=0.126$ and $\Phi_{2}=0.050$ are obtained. Conversion of these values into the rate of $\mathrm{Si}$ removal gives $87.4 \%$ for 1 lance and $95 \%$ for 2 lances. These are very close approximation to $88.9 \%$ and $92.2 \%$ which are the mean values of experiments Nos. 2 and 6, and Nos. 3 and 4 , respectively. This means that $\alpha_{\mathrm{Si}}=0.007$ is adequate as the resistance coefficient for the reaction of Si removal. For 3 lances with the same values of the parameter and operation variables as above, $\mathrm{Si}$ removal rate becomes $97.3 \%$. $\quad \alpha_{\mathrm{Si}}$ for experiment No. 1 is low as seen in Table 3. The reason for this would be that the rate of oxygen supply exceeded that equivalent to the desiliconization, providing stronger bath mixing.

Removal rates of $\mathrm{Mn}$ and $\mathrm{P}$ are lower than that of Si because concentrations of $\mathrm{Mn}$ and $\mathrm{P}$ in equilibrium with slag can not be, unlike $\mathrm{Si}$, regarded as 0 . However, similar with the reaction of Si removal, blowing with multiple lances in series would be advantageous for the removal of $\mathrm{Mn}$ and $\mathrm{P}$.

\section{Experiments with 1 Lance}

From the comparison between experiments Nos. 2 and 6 which are operated under the same conditions, the followings are observed: The removal rate of each element is better for experiment No. 2, whereas the oxygen efficiency (amount of oxygen required for removing $\mathrm{C}, \mathrm{Si}, \mathrm{Mn}$ and $\mathrm{P} /$ total amount of oxygen blown) is better for experiment No. 6. This seems to be caused by the fact that input concentrations of $\mathrm{C}$, Si and $\mathrm{P}$ and temperature of hot metal in experiment No. 6 were higher than those in experiment No. 2.

Experiment No. 1 showed the highest oxygen efficiency in spite of the excess blowing of oxygen under hard blowing condition like in experiment No. 5 . The difference between experiments Nos. 1 and 5 seems to be explained by the facts that the mixing by $\mathrm{CO}$ boil in No. 1 was stronger than that in No. 5 since the blowing rate for the former was in the range where C removal is promoted, whereas the blowing condition for No. 5 was excessively hard as shown in Table 6. Though intensive $\mathrm{CO}$ boiling taking place in the output $\mathrm{C}$ range for experiment No. 1 was expected to make total iron content in the slag (T.Fe) lower than that in other experiments, such difference could not be observed. This absence of difference would be in the cause that the furnace is so long for hard blowing that the mixing of longitudinal direction is inadequate. This is the same in experiment No. 5. In both cases, oxygen jet collided with the bottom of the furnace tends to escape upward before fully captured and has minor contribution to the longitudinal mixing. Sticking of iron droplets onto the lance and the ceiling refractories was most marked in experiment No. 5 and significantly different from that in other experiments.

Operational conditions for experiments Nos. 2 and 6 were considered more suitable for the furnace shape than those for experiments Nos. 1 and 5. It is, however, difficult to cover the wide span of operational conditions by only 1 lance. Multiple lances operation can solve this difficulty even with one stage trough type furnace.

Especially low removal rate of $\mathrm{C}$ in experiment No. 5 seems to be brought by the reason that oxygen was not consumed for decarburization because the oxygen blown was not fully captured, selective oxidation of $\mathrm{Si}, \mathrm{Mn}$ and $\mathrm{P}$ took place, and moreover, the mixing between slag and metal was insufficient.

\section{Experiments with 2 Lances}

Comparison of 2 lances operations between ex-

\begin{tabular}{|c|c|c|c|c|c|c|}
\hline Number of experiment & 1 & 2 & 3 & 4 & 5 & 6 \\
\hline$n$ & 1 & 1 & 2 & 2 & 1 & 1 \\
\hline$V_{\mathrm{O}_{2}}(\mathrm{~kg} / \mathrm{min})$ & 1.44 & 0.981 & 0.930 & 0.991 & 1.02 & 0.971 \\
\hline$V_{\mathrm{CO}}(\mathrm{kg} / \mathrm{min})$ & 1.66 & 0.807 & 0.625 & 0.820 & 0.503 & 0.844 \\
\hline Q $\quad(\mathrm{kg} / \mathrm{min})$ & 33.5 & 37.6 & 33.5 & 37.8 & 37.2 & 37.7 \\
\hline$\Phi$ & 0.0304 & 0.0862 & 0.0797 & 0.0758 & 0.172 & 0.137 \\
\hline$\alpha_{\mathrm{Si}}$ & 0.0030 & 0.0045 & 0.0091 & 0.0091 & 0.0085 & 0.0076 \\
\hline
\end{tabular}

Table 3. Calculation of $\alpha_{\mathrm{Si}}$ 
periments Nos. 3 and 4 shows that experiment No. 3 was subjected to relatively soft blow. As shown in Table 2, (T.Fe) in slag in experiment No. 3 was higher than that in experiment No. 4, and experiment No. 3 attained the 2 nd best dephosphorization rate after experiment No. 1. Output P levels in experiments Nos. 3 and 4 are, however, equal.

The oxygen efficiency for experiment No. 3 is low next to that for experiment No. 5. Seemingly, this is caused by the smaller hot metal input rate. However, as the metal hold-up weight is equal to that in other experiment, the low oxygen efficiency seems to be due primarily to the fact that the blowing condition for experiment No. 3 was the softest as shown in Table 6. Since (T.Fe) in experiment No. 3 is similar to that in other experiments but No. 4, blowing for No. 3 is not extreemly soft. Therefore, observed high dephosphorization rate for No. 3 is resulted from the fairly high (T.Fe) and the effect of 2 lances.

Rate of lime input, rate of phosphorus removal, and the effective concentration of (T.Fe) per hot metal input rate were calculated to compare experiment No. 3 with experiment No. 4 under the same conditions. The results are indicated in Table 4. The effective concentration of (T.Fe) is expressed by the ratio $(\%)$ of (T.Fe) for experiments Nos. 3 and 4 to slag rate observed in experiment No. 3, and the calculation was carried out based on the assumption noted below the table. Requisite for the continuous dephosphorization process is to establish the optimum operational conditions which lower the decarburization, the consumption of lime and the generation of T.Fe, and promote dephosphorization at most under high oxygen efficiency. From this point of view, it can be said that experiment No. 3 is advantageous for the smaller decarburization and lime addition and better dephosphorization, whereas experiment No. 4 is advantageous for limited formation of T.Fe and better oxygen efficiency.

From the above considerations, the optimum operational conditions seems to lie in between the two experimental conditions. It will, however, be possible to get a product with lower $\mathrm{P}$ than this campaign by the use of higher basicity slag which will become available in larger furnace capacity where more amount of lime can be fused. Moreover, it can be

Table 4. Dephosphorization in the 2 lances operations

\begin{tabular}{|c|c|c|}
\hline Number of experiment & 3 & 4 \\
\hline $\begin{array}{l}\text { Input rate of lime to that of } \\
\text { hot metal } \quad(\mathrm{kg} \text { lime } / \mathrm{kgHM})\end{array}$ & 0.0577 & 0.0669 \\
\hline Input rate of $\mathrm{P}$ & 0.0469 & 0.0454 \\
\hline Removal rate of $\mathrm{P}$ & 0.0345 & 0.0314 \\
\hline T.Fe & 20.94 & 14.03 \\
\hline $\begin{array}{r}\text { Effective concentration of T.Fe* } \\
(\%)\end{array}$ & 20.94 & 17.54 \\
\hline $\mathrm{O}_{2}$ efficiency & 72.0 & 82.0 \\
\hline
\end{tabular}

* Calculated by assuming that the slag output rate of in Exp. No. 4 is $25 \%$ more than that of in Exp. No. 3, since the aimed flux rate for Exp. No. 4 is $5 \mathrm{~kg} / \mathrm{min}$ while that for Exp. No. 3 is $4 \mathrm{~kg} / \mathrm{min}$. said that experiments Nos. 3 and 4 propose the problem on which side the base of the operation should be taken to get the economically optimum condition for dephosphorization, i.e., hard blow with much amount of lime addition or soft blow with (T.Fe) enriched in the slag.

As for the reduction rates of other elements, no significant difference is observed except for a little advance of decarburization in experiment No. 4.

\section{Relative Removal Rate of $\mathrm{P}$}

Relative removal rate of $\mathrm{P}$ is defined as the ratio of the rate of removal of $\mathrm{P}$ to that of other elements, and is listed at the lowest part of Table 2. High level of this value means that the dephosphorization proceeds more than the oxidation of other elements do, and hence this can be an index to judge whether or not the process is suitable for dephosphorization. However, output $\mathrm{P}$ level, oxygen efficiency and residual level of $\mathrm{C}$ which is used as the heat source in the next process should be examined at first. From above point of view, experiment No. 3 seems to have been carried out under the most suitable conditions for dephosphorizing among 6 experiments in Table 2. That is, experiment No. 3 gives not only high relative rate of $\mathrm{P}$ removal, but also low $\mathrm{P}$ level and high absolute rate of dephosphorization as listed in Table 4.

Relative removal rate of $\mathrm{P}$ to $\mathrm{Si}$ or $\mathrm{P}$ to $\mathrm{Mn}$, i.e., the rate of removal of $\mathrm{P}$ as compared to that of $\mathrm{Si}$ or $\mathrm{Mn}$ in experiments Nos. 2 and 6 is similar to that in experiment No. 4. Relative removal rate of $\mathrm{P}$ to $\mathrm{C}$ in experiment No. 5 is as high as that in experiment No. 3. This arises from the low oxygen efficiency observed in experiment No. 5, i.e., $\mathrm{Si}$ and $\mathrm{Mn}$ are selectively oxidized and $\mathrm{C}$ can not get a share of oxygen. The maximum relative removal rate of $\mathrm{P}$ to $\mathrm{Si}$ or $\mathrm{P}$ to $\mathrm{Mn}$ is obtained in experiment No. 1 because the higher oxygen rate promoted the removal of $\mathrm{P}$, either. This is apparent from the minimum relative removal rate of $\mathrm{P}$ to $\mathrm{C}$, and hence operation like experiment No. 1 is concluded far from the present aim of preliminary dephosphorization which must save $\mathrm{C}$ as a heat source in the next stage.

The dephosphorization in experiment No. 1 is, however, most advanced under the observed T. Fe level similar to that in other experiments. Though $\mathrm{CaO} / \mathrm{SiO}_{2}$ for experiment No. 1 is high, all slags used in the present experiments are considered to have similar capability to remove $\mathrm{P}$ as shown in the paper of Nakajima et al. ${ }^{9)}$ in which the peak of dephosphorization is at $\mathrm{CaO} / \mathrm{SiO}_{2}=2.5$. The advance of dephosphorization in experiment No. 1 irrespective of the identical basicity is due to the strong $\mathrm{CO}$ boil that makes bath mixing active and promotes slagmetal reactions. From this, as Kato et al. ${ }^{10)}$ have reported about the promotion of $\mathrm{P}$ removal in $\mathrm{LD}$ converter, injection of inert gas or inert gas-oxygen mixture in the bath in front of slag off port of the continuous pre-dephosphorization furnace seems to have a merit to get higher iron yield, while oxygen blowing rate is kept minimum to depress the removal 
of $\mathrm{C}$ for the selective dephosphorization.

\section{Comparison with NRIM Process}

NRIM data given in Table 2 are the mean values of experiments Nos. 57 to 66 for the operation in the lst stage of NRIM continuous steelmaking process. ${ }^{4-6)}$ The operating conditions of 10 experiments differ from each other and range 2.2 to $2.4 \mathrm{Nm}^{3} / \mathrm{min}$ for the oxygen blowing rate and 9 to $13 \mathrm{~kg} / \mathrm{min}$ for the rate of addition of flux which consists of lime: fluorspar $=5 \sim 9: 1$.

The relative removal rate of $\mathrm{P}$ to $\mathrm{C}$ in the 1 st stage is similar to that in the present experiments. This is the case for the relative removal rate of $\mathrm{P}$ to $\mathrm{Si}$. However, the relative removal rate of $\mathrm{P}$ to $\mathrm{Mn}$ in the lst stage is about twice as much as that in the present work. This would be caused by the simultaneous injection of flux powder with oxygen gas in the lst stage. The ratio of the oxygen blowing rate to the hot metal input rate is $18 \mathrm{~N} l / \mathrm{kgHM}$ in both cases. Nevertheless, desiliconization in the 1st stage is more proceeded perhaps because of the effect of 4 lances as stated in $I I I .1$. 1. On the contrary, the delay of $\mathrm{Mn}$ oxidation is brought by the selective oxidation of $\mathrm{P}$ by means of the injection of powder flux and high equilibrium concentration of $\mathrm{Mn}$ with slag $(0.12 \%)$ under low T.Fe operation. This explains why in the lst stage other elements were oxidized prior to the oxidation of Mn under the same oxygen efficiency as that in the present experiments. Concentration of T.Fe of as low as $1 / 4$ of the present results seems to be the characteristics of the 1st stage of NRIM process, and this results from the fact that the ratio of the oxygen blowing rate to the hot metal input rate per 1 lance in the 1st stage is $4.6 \mathrm{~N} / / \mathrm{kgHM}$, whereas 2 to 4 times as much is blown in the present operations. That is, the blowing condition in the lst stage is not suited for the formation and survival of $(\mathrm{FeO})$ because oxygen blowing rate is small, and, as previously mentioned, slag-metal reactions are proceeded by 4 lances and hence the formation of (FeO) is prohibited. Low T.Fe observed in experiment No. 4 in which jet penetration depth is close to that in the 1st stage can be similarly explained. The assumption that the penetration depth in the two cases are similar to each other is derived from the fact that oxygen blowing rate per 1 lance in the 1st stage is similar to those in experiments Nos. 2 and 4 and that the penetration depth in No. 4 is just a little deeper than that in Nos. 2 and 6 as shown in Table 6.

It can be concluded that the preliminary dephosphorization furnace can provide a relative removal rate of $\mathrm{P}$ to $\mathrm{C}$ comparable with that of the 1st stage in spite of its small scale, and much amount of additives for the faster slag formation and smaller rate of $\mathrm{CaO}$ input to the hot metal to cover the disadvantage of granular fluxes. Thus, it would be possible to develop an operation with higher relative removal rate of $\mathrm{P}$ by increasing lance number, adopting of flux powder and modifying blowing condition. Moreover, an operation procedure which utilizes $\mathrm{Mn}$ as the heat source in the next stage by regulating the slag composition and temperature would be also possible due to the high residual level of $\mathrm{Mn}$ in the lst stage.

\section{Equilibrium with Slag}

Concentrations of $\mathrm{O}, \mathrm{Mn}$ and $\mathrm{P}$ in equilibrium with each slag are shown in Table 5. Equilibrium equations used are of Gakushin ${ }^{11)}$ for $\mathrm{O}_{e q}$ and $\mathrm{Mn}_{e q}$, and of $\mathrm{Healy}^{12)}$ for $\mathrm{P}_{e q}$, respectively.

As for the 2 lances operation, $\mathrm{Si}$ and $\mathrm{Mn}$ are removed more in experiment No. 4 than in experiment No. 3 in spite of low $\mathrm{O}_{e q}$ and high $\mathrm{Mn}_{e q}$ and $\mathrm{P}_{e q}$ brought by low T. Fe. $\mathrm{P}$ in No. 4 is also removed as much as that in No. 3. This would be due to the difference in the degree of mixing as stated in III. 1. 3 . As $\mathrm{Mn}_{e q}$ for experiment No. 4 is close to output $\mathrm{Mn}$ level, there remains a possibility to retain $\mathrm{Mn}$ in the treated hot metal.

On the contrary, since $\mathrm{P}_{e q}$ is as low as $1 / 50$ to $1 / 100$ of $\underline{P}$ in all experiments, the influence at the reaction interface of concentration change, which is one of the factors affecting the mass transfer limited reaction rate, on the dephosphorization rate is negligible. Therefore, if Healy's equation is suitable to obtain $\mathrm{P}_{e q}$ under high $\mathrm{C}$, low temperature bath condition, the most effective factor to improve the dephosphorization with conventional steelmaking slag is the mixing strength.

\section{Lancing Condition}

To estimate the effect of the number of lance on the advance of the continuous steelmaking reactions at a same oxygen blowing rate, the lancing condition should be chosen to make the condition of mixing with metal bath the same. As previously stated, the standard of mixing strength in this campaign is, by adjusting the lance height for experiment No. 3, to get the same velocity at the metal surface as that for experiment No. 2. Lance height, $50 \mathrm{~mm}$, of 2 lances operations decided from the above criterion was already experienced in the continuous steelmaking experiments ${ }^{13-15}$ at its beginning, so that there was not further trouble during the operation.

It is difficult to express the mixing strength of the process where 2 liquid phases are stirred by gas like in the steelmaking furnace. Here, by the use of an experimental equation (3) for the penetration depth $L$ as reported by Segawa, ${ }^{16}$ ) the relations between $L$ calculated on various assumptions and lance height $h$ are given in Table 6.

$$
L=L_{h} \exp \left(-0.78 h / L_{h}\right)
$$

where, $\quad L_{h}=63.0\left(F_{\mathrm{O}_{2}} / d\right)^{2 / 3}$

Table 5. Concentrations in equilibrium with slag

\begin{tabular}{|c|c|c|c|c|c|c|c|}
\hline \multicolumn{2}{|c|}{$\begin{array}{l}\text { Experiment } \\
\text { number }\end{array}$} & 1 & 2 & 3 & 4 & 5 & 6 \\
\hline $\mathrm{O}_{e q}$ & $(\%)$ & 0.089 & 0.091 & 0.073 & 0.051 & 0.072 & 0.094 \\
\hline $\mathrm{Mn}_{e q}$ & $(\%)$ & 0.025 & 0.033 & 0.030 & 0.064 & 0.029 & 0.043 \\
\hline $\mathrm{P}_{e q}(\times 10$ & $-4 \%)$ & 4.5 & 7.0 & 3.8 & 6.0 & 8.7 & 4.7 \\
\hline
\end{tabular}


Table 6. Calculated results of cavity depth and lance height

Experiment number

1

2.6

3

4

5

\begin{tabular}{|c|c|c|c|c|c|c|c|}
\hline \multicolumn{8}{|c|}{ Blowing conditions } \\
\hline & $d$ & $(\mathrm{~mm})$ & 4.9 & 4.9 & 4.9 & 3.4 & 3.4 \\
\hline & $h$ & $(\mathrm{~mm})$ & 150 & 150 & 50 & 50 & 150 \\
\hline \multirow{2}{*}{$a$} & $v_{0}$ & $(\mathrm{~m} / \mathrm{sec})$ & 884 & 618 & 309 & 642 & 1284 \\
\hline & $L$ & $(\mathrm{~mm})$ & 236 & 170 & 131 & 176 & 238 \\
\hline \multirow{2}{*}{$b$} & $L$ & $(\mathrm{~mm})$ & & 170 & 117 & 142 & 204 \\
\hline & $h$ & $(\mathrm{~mm})$ & & 150 & 75 & 108 & 216 \\
\hline \multirow{2}{*}{$c$} & $L$ & $(\mathrm{~mm})$ & & 170 & 120 & 120 & 170 \\
\hline & $h$ & $(\mathrm{~mm})$ & & 150 & 69 & 153 & 289 \\
\hline \multirow{2}{*}{$d$} & $L$ & $(\mathrm{~mm})$ & & 170 & 135 & 135 & 170 \\
\hline & $h$ & & & 150 & 44 & 122 & 289 \\
\hline \multirow{2}{*}{$e$} & $L$ & $(\mathrm{~mm})$ & & 170 & 170 & 170 & 170 \\
\hline & $h$ & $(\mathrm{~mm})$ & & 150 & -11 & 60 & 289 \\
\hline
\end{tabular}

$a$ : Obtained by substituting actual data into Eq. (3).

$b$ : The jet velocity at the surface of still bath is equal for all experiments.

$c:$ The cross sectional area of the cavity is equal for all experiments.

$d:$ The volume of the cavity is equal for all experiments.

$e$ : The cavity depth is equal for all experiments. The base is experiment No. 2 .

The values in row $a$ in Table 6 is obtained by substituting the operational conditions into Eq. (3), $v_{0}$ is the gas velocity at the nozzle outlet calculated by assuming incompressible fluid. From these results, jet seems to reach to the bottom of the furnace except for experiment No. 3. As a hollow of about $4 \mathrm{~cm}$ depth was observed in experiment No. 5, these calculated values would be reasonable.

The values on rows $b$ to $e$ indicate the penetration depth and lance height required to get the same mixing strength as that of No. 2 under the condition for the number and nozzle diameter of lance used for experiments No. 3 to No. 5. The values on row $b$ are obtained by assuming that the velocity at the still bath surface is the same as that of experiment No. 2. The obtained values show that the lance height for experiment No. 3 was lower than that for other experiments. To calculate the values on row $c$, cavity shape is assumed similar to each other and its sectional area (in the case of 2 lances operation, the sum of two sectional areas) is assumed equal to that of No. 2. This means that the value of $L^{2}$ is equal to each other. Consequently, the values on row $c$ become identical to the values obtained by making the kinetic energy in the bath the same as that for experiment No. 2 on the assumption that the penetration depth is, as observed in Segawa's water model experiments, ${ }^{16)}$ proportional to the velocity of the metal flow in the bath. For the values on row $d$, the cavity volume is assumed equal, and for those on row $e$, the penetration depth is assumed equal to each other. As the lance height chosen for experiment No. 3 is in the middle of that for the cases $b$ to $e$, the choice may have been appropriate.

\section{On the Optimum Operating Conditions}

Though the number of experiments is not many, the optimum operational conditions for the continuous preliminary dephosphorization process can be derived as follows from the above discussions.

(1) Lancing condition:

Hard blow seems to be preferable to soft blow. In LD operation, soft blow is indispensable for the fast slag formation. However, as fused slag always exists in the continuous process, blowing to increase (FeO) is not necessary, so that hard blow is preferable to increase the opportunity of contact between metal and slag for promoting the reaction. As for lance number, the use of multiple lances $(2 \sim 4)$ is advantageous for promoting the slag-metal reaction as mentioned in III. 1. 1. Injection of inert gas or flux powder with oxygen gas seems to be effective to making the bath mixing harder. It is desirable to keep the oxygen blowing rate lower than 15 to $20 \mathrm{Nm}^{3} / \mathrm{tHM}$ to retain the heat source for the next decarburization furnace.

(2) Slag compositions:

It is possible to keep (FeO) lower than $10 \%$ as observed in NRIM operation shown in Table 2, because it is not required for the reduction of $\mathrm{P}$, under the conditions of low temperature and high $\mathrm{C}$ content like this campaign, to decrease the $\mathrm{P}$ level in equilibrium with slag by the increased ( $\mathrm{FeO}$ ) to compensating the temperature rise as observed in blowing low $\mathrm{C}$ steel in LD operation. Consequently, $(\mathrm{CaO})$ relatively increases to result in high basicity slag with $\mathrm{CaO} / \mathrm{SiO}_{2} \geqq 3$, enhancing the dephosphorization. However, slag fluidity should be improved since temperature in this case is low. 
(3) Metal compositions:

When the input $\mathrm{P}$ level is increased, the rate of $\mathrm{CaO}$ input and intensity of the bath mixing should be increased to prevent the increase of output P level. To retain some of $\mathrm{Mn}$ is desirable as the heat source in the next process as stated in III. 4 .

(4) Temperature:

As the metal and slag were kept fluid when the output temperature was over $1450^{\circ} \mathrm{C}$ in the present scale of experiment, it would be possible to operate at lower temperature in larger scale experiments.

(5) Others:

The use of too many lances invites heat loss. As for the furnace shape, a trough- or a boat-type ${ }^{6)}$ is recommendable.

\section{Conclusion}

From only 6 operations, characteristic observation could be obtained. As expected from the resistance model ${ }^{8)}$ it becomes clear that multiple lance operation is advantageous for the promotion of slag-metal reaction. It can be concluded from these operations that the condition required for continuous dephosphorization is to reduce the formation of bubbles to suppress the decarburization and to intensify the mixing between metal and slag. Under the above condition, the continuous pre-dephosphorization process can remove $\mathrm{P}$ selectively with minimized oxidation of C. Through the comparison with the lst stage of NRIM process, capability of the present process to retain some amount of $\mathrm{Mn}$ in the melt is confirmed.

The greatest advantage of the continuous dephosphorization process is that flux materials can be easily fused under the existence of fused slag, resulting in the optimum slag condition for the dephosphorization. If the countercurrent operation, which could not be tested because of lay-out limitation, were examined in the 2 lances experiment, more desirable results in the oxygen efficiency and the dephosphorization rate could be obtained as in the previous reports. ${ }^{8,17,18)}$

As a consequence, a desirable form of the practical continuous dephosphorization process should meet the following requirements:

1) one stage trough type furnace, since tanks in series type is thermally disadvantageous;

2) to set up 2 4 lances in series (in the bottom blowing, nozzle number will be increased) and to blow with all lances at equal gas-liquid flow rate ratio;

3) simultaneous feeding of flux with oxygen.

Moreover, the use of countercurrent operation together with inert gas injection is suggested to promote the slag-metal mixing. By optimization of these physical conditions, a process for preliminary treatment of hot metal is expected to be developed with superior dephosphorization capability.

\section{Nomenclature}

$d$ : nozzle diameter ( $\mathrm{mm}$ )

$\mathrm{FO}_{2}$ : oxygen blowing rate $\left(\mathrm{Nm}^{3} / \mathrm{h}\right)$

$h$ : lance height ( $\mathrm{mm})$

$L:$ penetration depth $(\mathrm{mm})$

$n$ : number of lances (or number of back-mix tanks)

$Q$ : hot metal input rate $(\mathrm{kg} / \mathrm{min})$

$R$ : transfer resistance $(\mathrm{min} / \mathrm{kg})$

$t$ : time $(\min )$

$V:$ gas rate $(\mathrm{kg} / \mathrm{min})$

$v_{0}$ : velocity at the top of the nozzle $(\mathrm{m} / \mathrm{sec})$

$W$ : hold-up weight $(\mathrm{kg})$

$\alpha$ : resistance coefficient (-)

A: gas-liquid flow rate ratio $(-)$

$\Phi$ : residual rate (-)

Subscript

$e q$ : equilibrium

in: input

out: output

\section{Acknowledgements}

The authors are grateful to Dr. T. Ueda, Chief of the 2nd Lab. of Process Development Div., NRIM, for his helpful advice. They also wish to thank the members of Process Development Div., especially Mr. Y. Shimamura and Mr. A. Kasahara, for their contributions to carrying out the experiments.

\section{REFERENCES}

1) R. Iida, T. Imai, F. Sudo, K. Suzuki and A. Ejima: Tetsuto-Hagané, 62 (1976), A9.

2) T. Takano, A. Kawami, T. Ikeda, A. Okazaki and T. Matsuo: Tetsu-to-Hagané, 62 (1976), A13.

3) H. Katayama, M. Inatomi, H. Kajioka, S. Yamamoto and H. Tanaka: Tetsu-to-Hagané, 62 (1976), A17.

4) R. Nakagawa, S. Yoshimatsu, T. Ueda, T. Mitsui, A. Fukuzawa, A. Sato and T. Ozaki: Tetsu-to-Hagané, 59 (1973), 414; Trans. ISIJ, 13 (1973), 333.

5) S. Yoshimatsu, R. Nakagawa, T. Ueda, T. Mitsui, A. Fukuzawa, A. Sato and T. Ozaki: Report of the 19th Comm. of Japan Soc. for the Promotion of Science, (1973), No. 9575.

6) T. Mitsui, T. Watanabe, Y. Iwai, Y. Endo, H. Sugimoto and H. Kojima: Taikabutsu (Refractories), 29 (1977), 291.

7) A. Fukuzawa, R. Nakagawa, S. Yoshimatsu and T. Ueda: Tetsu-to-Hagané, 63 (1977), 63; Trans. ISIJ, 18 (1978), 189.

8) A. Fukuzawa, R. Nakagawa, S. Yoshimatsu and T. Ueda: Tetsu-to-Hagané, 64 (1978), 1333.

9) H. Nakajima, M. Doi, A. Horikawa, T. Kuwabara and T. Furusaki: Tetsu-to-Hagané, 53 (1967), 317.

10) T. Kato, J. Imai and K. Fujiwara: Tetsu-to-Hagané, 48 (1962), 465.

11) Seiko-han'no no Suisho Heikochi, ed. by Seiko 19th Comm. of Japan Soc. for the Promotion of Science, Nikkan Kogyo Shinbunsha, Tokyo, (1968).

12) G. W. Healy: JISI, 172 (1970), 664.

13) R. Nakagawa, T. Ueda, S. Yoshimatsu, T. Mitsui, I. Uehara, A. Fukuzawa and Y. Nakamura: Kinzaigiken Kenkyuhokoku, 10 (1967), 557.

14) R. Nakagawa, T. Ueda, S. Yoshimatsu, T. Mitsui, I. Uehara, A. Fukuzawa and Y. Nakamura: Tetsu-to-Hagané, 54 (1968), S481.

15) R. Nakagawa, S. Yoshimatsu, T. Mitsui, I. Uehara, A. Fukuzawa and Y. Nakamura: Tetsu-to-Hagané, 56 (1970), S64.

16) K. Segawa: Tetsuyakin Han'nokogaku, Nikkan Kogyo Shinbunsha, Tokyo, (1969), 114.

17) J. Szekely: Heat and Mass Transfer in Process Metallurgy, ed. by A.W.D. Hills, Inst. Mining and Metallurgy, London, (1967), 115

18) H. K. Worner, F. H. Baker, I. H. Lassam and R. Siddons: J. Metals, 22 (1969), No. 6, 50.

19) H. S. Mcklay, T. K. Sherwood and C. E. Reed: Applied 
Mathematics in Chemical Engineering, McGraw-Hill Book Co., New York. (1957), 325.

\section{Appendix}

The assumptions involved in the resistance model ${ }^{7,8)}$ concerning the desiliconization are as follows:

(1) One lance constitutes one back-mix tank, where compositions in metal and slag are uniform, and temperatures of metal, slag and exhaust gas are equal.

(2) The mixing characteristics of the continuous steelmaking furnace with multiple lances in series can be represented by the back-mix tanks in series, each tank corresponds to one lance.

(3) Steelmaking reactions are controlled by the mass transfer: The reaction rate is proportional to the difference in reactant concentrations between steel bath and slag, and in inverse proportion to the transfer resistance.

(4) The transfer resistance for slag-metal reactions is inversely proportional to the sum of the exhaust gas rate and oxygen blowing rate.

On the basis of the above assumptions, the $\mathrm{Si}$ balance for 1 lance in the continuous steelmaking process is given by the following equation:

$$
\begin{aligned}
d W \mathrm{Si}_{\text {out }} / d t= & Q_{\text {in }} \mathrm{Si}_{\text {in }}-Q_{\text {out }} \mathrm{Si}_{\text {out }} \\
& -\left(\mathrm{Si}_{\text {out }}-\mathrm{Si}_{\text {eq }}\right) / R_{\mathrm{Si}}
\end{aligned}
$$

where, $\quad R_{\mathrm{Si}}=\alpha_{\mathrm{Si}} /\left(V_{\mathrm{O}_{2}}+V_{\mathrm{CO}}\right)$

The residual rate of $\mathrm{Si}, \Phi$, is given by $\mathrm{Eq}$. (1) on the assumption that $Q_{i n}=O_{o u t}=Q$ and $\mathrm{Si}_{e q}=0$ at steady state.

In $n$ back-mix tanks in series model or a trough type model with $n$ lances in series, analytical consideration to find suitable distribution of the over-all gasliquid flow rate ratio, $A$, which is assumed constant, or the consideration to find suitable distribution of $V_{\mathrm{O}_{2}}+V_{\text {co }}$ \{since $Q$ seems constant to each lance (tank)\} to make the residual rate of $\mathrm{Si}$ minimum is as follows: ${ }^{19)}$

By defining the gas-liquid flow rate ratio for the $i$-th lance as $\Lambda_{i}$, residual rate of lance $\left(\Phi_{i}\right)$ is given by

$$
\Phi_{i}=1 /\left(1+\Lambda_{i} / \alpha_{\mathrm{Si}}\right)
$$

The residual rate as a total is expressed by

$$
\begin{aligned}
& \Phi=\Phi_{1} \Phi_{2} \cdots \cdots \Phi_{i} \cdots \cdots \Phi_{n} \\
& =1 /\left\{\left(1+\Lambda_{1} / \alpha_{\mathrm{Si}}\right)\left(1+\Lambda_{2} / \alpha_{\mathrm{Si}}\right) \cdots \cdots\left(1+\Lambda_{i} / \alpha_{\mathrm{Si}}\right) \cdots \cdots\right. \\
& \left.\cdots \cdot\left(1+\Lambda_{n} / \alpha_{\mathrm{Si}}\right)\right\}
\end{aligned}
$$

The minimum will be given when the total differential of Eq. (A-3) satisfies the following equation:

$$
\begin{aligned}
d \Phi & =\sum_{i=1}^{n} \frac{\partial \Phi}{\partial \Lambda_{i}} d \Lambda_{i}=0 \ldots \ldots \ldots . . \\
\partial \Phi / \partial \Lambda_{i} & =-1 /\left\{A \alpha_{\mathrm{Si}}\left(1+\Lambda_{i} / \alpha_{\mathrm{Si}}\right)\right\}
\end{aligned}
$$

where, $\quad A=\left(1+\Lambda_{1} / \alpha_{\mathrm{Si}}\right)\left(1+\Lambda_{2} / \alpha_{\mathrm{Si}}\right) \cdots \cdots\left(1+\Lambda_{n} / \alpha_{\mathrm{Si}}\right)$

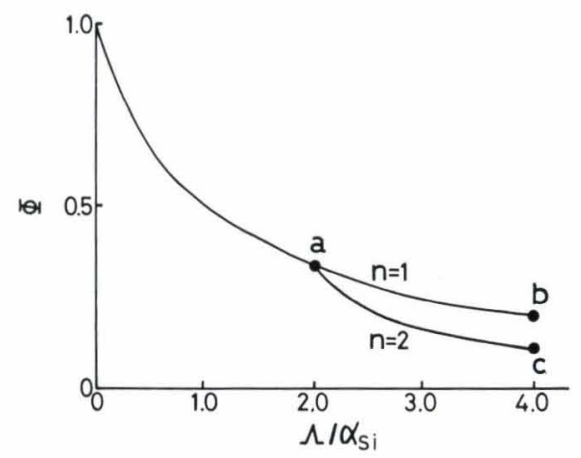

Fig. A-1. Comparison of residual rates of $\mathrm{Si}, \Phi$, between 1 and 2 lances operations when $\Lambda / \alpha_{\mathrm{Si}}=4: \Phi_{a}=$ $0.333, \Phi_{b}=0.2, \Phi_{c}=0.111$

Combination of Eqs. (A-4) and (A-5) gives

$$
d \Phi=\frac{-1}{A \alpha_{\mathrm{Si}}} \sum_{i=1}^{n} \frac{d \Lambda_{i}}{1+\Lambda_{i} / \alpha_{\mathrm{Si}}}=0
$$

From the definition,

$$
\sum_{i=1}^{n} \Lambda_{i}=\Lambda=\mathrm{constant}
$$

and

$$
\sum_{i=1}^{n} d \Lambda_{i}=0
$$

From Eq. (A-8), it follows that

$$
d \Lambda_{n}=-\sum_{i=1}^{n-1} d \Lambda_{i}
$$

Combination of Eqs. (A-6) and (A-9) gives

$$
d \Phi_{n}=\frac{-1}{A \alpha_{\mathrm{Si}}} \sum_{i=1}^{n-1}\left\{\left(\frac{1}{1+\Lambda_{i} / \alpha_{\mathrm{Si}}}-\frac{1}{1+\Lambda_{n} / \alpha_{\mathrm{Si}}}\right) d \Lambda_{i}\right\}=0
$$

To keep identity of this equation, the sum of the coefficients of each term must be zero. That is,

$$
\Lambda_{i}=\Lambda_{n}
$$

Under this condition Eq. (A-10) is made valid. Referring to Eq. (A-7), $A_{i}$ for minimizing $\Phi$ is given by

$$
\Lambda_{i}=\Lambda / n
$$

From the above, the maximum desiliconization rate is shown to occur when the gas-liquid flow rate ratio of each lance is kept equal. As $Q$ seems to be constant, blowing more oxygen gas from the lance situated at hot metal inlet side would be better to keep $\Lambda_{i}$ equal since the removal of $\mathrm{Si}$ proceeds prior to that of $\mathrm{C}$. The relations between $\Lambda / \alpha_{\mathrm{Si}}$ and $\Phi$ are shown in Fig. A-1, when the number of lances is 1 and 2 , and $\Lambda / \alpha_{\mathrm{Si}}=4$. In this case, the desiliconization rate is increased by $9 \%$ by the adoption of 2 lances. 